CLINICAL STUDY

\title{
Polymorphisms in the endocannabinoid receptor 1 in relation to fat mass distribution
}

\author{
M Frost, T L Nielsen, K Wraae, C Hagen ${ }^{1}$, E Piters ${ }^{2}$, S Beckers ${ }^{2}$, F De Freitas ${ }^{2}$, K Brixen, W Van Hul ${ }^{2}$ and M Andersen \\ Department of Endocrinology, Odense University Hospital, DK-5000 Odense C, Denmark, ${ }^{1}$ Department of Endocrinology, Bispebjerg Hospital, 2400 \\ Copenhagen, Denmark and ${ }^{2}$ Department of Medical Genetics, University of Antwerp, 26100 Antwerp, Belgium
}

(Correspondence should be addressed to M Frost; Email: frostnielsen@yahoo.com)

\begin{abstract}
Objective: Both animal and human studies have associated the endocannabinoid system with obesity and markers of metabolic dysfunction. Blockade of the cannabinoid receptor 1 (CB1) caused weight loss and reduction in waist size in both obese and type II diabetics. Recent studies on common variants of the $\mathrm{CB} 1$ receptor gene (CNR1) and the link to obesity have been conflicting. The aim of the present study was to evaluate whether selected common variants of the CNR 1 are associated with measures of obesity and fat distribution.

Design and methods: The single nucleotide polymorphisms (SNPs) rs806381, rs10485179 and rs1049353 were genotyped, and body fat and fat distribution were assessed by the use of dual-energy X-ray absorptiometry and magnetic resonance imaging in a population-based study comprising of 783 Danish men, aged 20-29 years.

Results: The rs806381 polymorphism was significantly associated with visceral fat mass (FM) only, whereas the rs1049353 was significantly and directly associated with visceral and intermuscular FM. None of the SNPs analysed were associated with total body FM or subcutaneous FM.

Conclusion: The results point towards a link between common variants of the CNR 1 and fat distribution in young men.
\end{abstract}

European Journal of Endocrinology 163 407-412

\section{Introduction}

The extensive distribution of the receptors in the endocannabinoid system reflects a profound complexity of the system regarding human physiology. The effects of the endocannabinoids are mediated via the endocannabinoid receptor 1 (CB1) and 2 (CB2). The $\mathrm{CB} 1$ is found in the brain, liver and muscle tissue, whereas the $\mathrm{CB} 2$ is present in monocytes as well as other cells of the immune system (1). Both animal and human studies have linked the endocannabinoid system with food intake, lipogenesis and addictive behaviour (2). Furthermore, activation of the $\mathrm{CB} 1$ may play a role in the development of insulin resistance in skeletal muscle (3). In placebo-controlled clinical trials, treatment with the CB1-selective antagonist rimonabant has resulted in reduction in body weight and waist circumference and improvement of cardio-metabolic risk factors including insulin sensitivity and lipid profile (4-7), and the appetite-suppressant effect of rimonabant has been shown to depend on CB1 (8). In contrast, treatment with a CB1 agonist is associated with an increase in hepatic lipogenesis in wild-type mice (9).

A limited number of studies have evaluated the contribution of common genetic variations (single nucleotide polymorphisms, SNPs) in the CNR1 gene on body composition. In a Belgian cohort, the CNR1 rs1049353 SNP was found to be associated with waist-to-hip ratio (WHR) in obese men (10). Likewise, in a study from Southern Italy (11), rs1049353 was linked with obesity; however, neither of these results were confirmed in studies on obese German children and adolescents (12) or mid-age American adults in the Framingham Study (13).

Müller et al. (12) found no association between the rs2023239 SNP and body mass index (BMI) in both children and adolescents. Similarly, this variant was not related to BMI in obese French children; however, the same study found an association between the same SNP and BMI in obese adults (14). In the same paper, associations with obesity and BMI in both children and adults were demonstrated for the rs806381 polymorphism. Whether an age-dependent association between these polymorphisms and BMI exists remains unresolved.

In the present study, we investigated whether the CNR1 rs806381, rs10485179 and rs1049353 SNPs in the CNR 1 were associated with fat distribution in a population-based sample of young, healthy Danish men. 


\section{Subjects and methods}

\section{Study population}

The Odense Androgen Study consists of a populationbased sample of Danish men. Complete information on the recruitment of the participants is available elsewhere (15). A random sample of 3000 men aged 20-29 years were issued a questionnaire covering demographics, life style factors and medical history. In all, 2042 men responded, and 783 of these respondents volunteered to participate in a clinical follow-up comprising: life style factors, past medical history including pharmacological treatments, physical examination; fasting blood samples covering haematology, hepatic, kidney and endocrine functions, lipids and glucose levels as well as blood for genetic analyses and densitometric evaluation of the body composition.

\section{Lifestyle factors}

On the basis of questionnaires and interviews during the clinical assessment, information on smoking was recorded as either never, previous or present use. Consumption of alcohol was noted as units consumed per week (one unit equalling $12 \mathrm{~g}$ of alcohol).

\section{Assessment of body composition}

Body weight and height were measured using standard equipment (Seca, Denmark, and Harpenden, Holtain, UK respectively) and BMI $\left(\mathrm{kg} / \mathrm{m}^{2}\right)$ was calculated as the body weight $(\mathrm{kg})$ divided by the square of the height $(\mathrm{m})$. Waist circumference was assessed during expiration between the iliac crest and the lower rib, while hip circumference was measured at the level of the greater trochanter.

A dual x-ray (DXA) densitometer (Hologic 4500, Hologic, Waltham, MA, USA) was used to asses total body fat mass (TBFM $(\mathrm{kg}))$.

Abdominal and femoral FM were further evaluated in the first 406 consecutively included participants using an open, low-field magnetic resonance imaging (MRI) unit (Magnetom Open Viva, Siemens, Erlangen, Germany) as reported previously (16). In short, abdominal visceral and subcutaneous FM were estimated using three T1-weighted 10-mm thick slices at the dorsal intervertebral space of L4/L5. Femoral intermuscular and subcutaneous FM were measured at an equidistant point between the patella and the greater trochanter. The results of the MRI measurements are reported as an area $\left(\mathrm{cm}^{2}\right)$.

\section{Laboratory methods}

Biological material was collected after an overnight fast of at least $8 \mathrm{~h}$ (between 0800 and $1000 \mathrm{~h}$ ). Serum and plasma were stored at $-80^{\circ} \mathrm{C}$.
Plasma glucose was measured using a hexokinasebased method (Integra 700, Roche). Serum cholesterol including low-density lipoprotein and high-density lipoprotein cholesterol was assessed using a homogenous enzymatic colourimetric method (Modular P $+\mathrm{E}$, Roche), while an enzymatic end point colourimetric method was used for the measurement of serum triglycerides (Modular P, Roche). Serum insulin was estimated using non-competitive immunoflourometric assays (Delfia, Wallac, Finland).

\section{Genotyping}

Standard methods were used to extract DNA from the blood of the participants. TaqMan assays (ABI, Foster City, CA, USA) were used to evaluate the genotypes of the CNR1 SNPs (rs806381, rs10485179 and rs1049353) on a LifeCycler LC 480 machine (Roche).

The validity of the analyses was checked by including both negative and positive controls in the investigations.

\section{Ethics}

The study was approved by the local ethics committee (files no. 20010198). All participants received written and oral information, and gave their consent in writing before inclusion. The study was registered in ClinicalTrials.gov (NCT00150163).

\section{Statistical analysis}

All computations were performed using STATA v. 10 (StataCorp LP, College Station, TX, USA). $P$ values of $<0.05$ were considered significant. Differences of parameters by genotypes were assessed by use of Kruskal-Wallis test, and testing for trends was used to evaluate the mode of inheritance. Furthermore, linear regression analysis was used to adjust for age, smoking status and alcohol consumption.

Table 1 General characteristics of the study population.

\begin{tabular}{|c|c|c|}
\hline & Median & $\begin{array}{c}25-75 \\
\text { percentiles }\end{array}$ \\
\hline Age (years) & 25.7 & $23.1-27.8$ \\
\hline Waist-to-hip ratio & 0.89 & $0.85-0.93$ \\
\hline BMI $\left(\mathrm{kg} / \mathrm{m}^{2}\right)$ & 24.3 & $22.5-26.7$ \\
\hline TBFM $(\mathrm{kg})$ & 13.81 & $10.43-17.93$ \\
\hline Visceral FM $\left(\mathrm{cm}^{2}\right)$ & 34.2 & $25.5-48.4$ \\
\hline Abdominal ScFM $\left(\mathrm{cm}^{2}\right)$ & 130.6 & $81.41-182.4$ \\
\hline Femoral ScFM $\left(\mathrm{cm}^{2}\right)$ & 51.4 & $37.6-70.2$ \\
\hline Intermuscular FM $\left(\mathrm{cm}^{2}\right)$ & 4.2 & $3.0-6.1$ \\
\hline Insulin (pmol/l) & 34.0 & $24-47$ \\
\hline Glucose $(\mathrm{mmol} / \mathrm{l})$ & 5.2 & $4.9-5.4$ \\
\hline HOMA (IR) & 1.10 & $0.75-1.52$ \\
\hline Triglycerides (mmol/l) & 1.00 & $0.71-1.40$ \\
\hline Cholesterol (mmol/l) & 4.6 & $4.0-5.2$ \\
\hline LDL (mmol/l) & 2.60 & $2.00-3.10$ \\
\hline $\mathrm{HDL}(\mathrm{mmol} / \mathrm{l})$ & 1.51 & $1.27-1.76$ \\
\hline
\end{tabular}




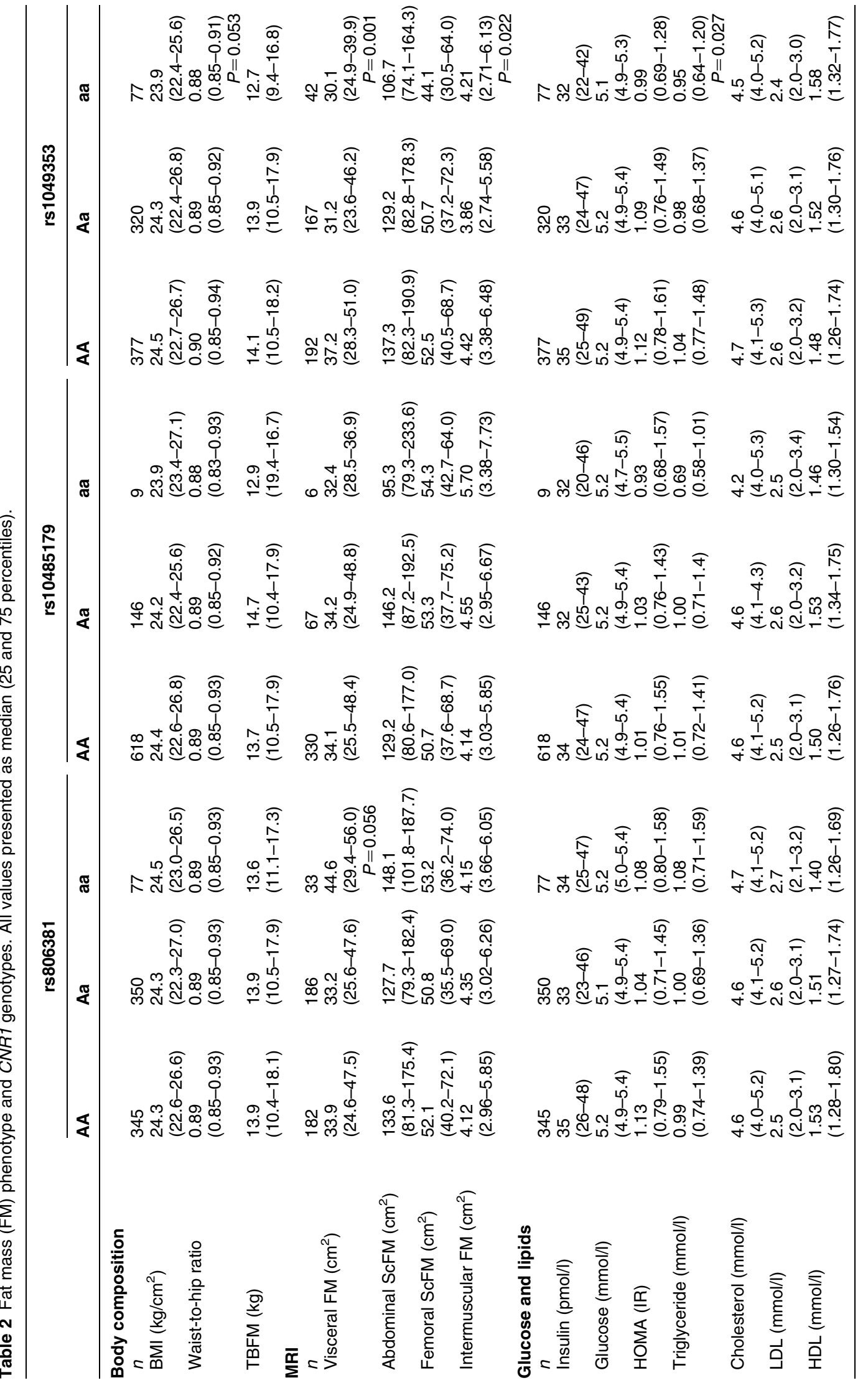


Acknowledging the imperfection of multiple testing, the investigation was focused on the relationship between genotypes and fat distribution measured by MRI, while other outcomes were given less weight as suggested by Altman (17).

\section{Results}

\section{Baseline data}

General information on the study population is presented in Table 1. Age of the participants ranged from 19.4 to 30.9 years of age with a median age of 25.7 years. The number of participants with a BMI $>25.0$ and $30.0 \mathrm{~kg} / \mathrm{m}^{2}$ was 39.7 and $7.9 \%$ respectively, and those with waist size exceeding $102 \mathrm{~cm}$ was $11.6 \%$. As previously described (15), the study population matched the background population on key points including age, BMI, physical activity, smoking and socio-economic status.

\section{Genotypes}

Genotyping was possible in more than $98.5 \%$ of the participants, and analyses demonstrated complete concordance between all duplicates. Furthermore, distributions of genotypes rs806381 ( $\mathrm{A}=$ major. $\mathrm{a}=$ minor. AA: $44.7 \%$, Aa: $45.3 \%$, aa: $10.0 \%$. A: $67.3 \%$, a: $32.8 \%$ ), rs 10485179 (A: $89.4 \%$, a: $10.6 \%$. AA: $80.0 \%$, Aa: $18.9 \%$, aa: $1.2 \%$ ) and rs 1049353 (A: $69.4 \%$, a: $30.6 \%$. AA: $48.7 \%$, Aa: $41.3 \%$ and aa: $10.0 \%)$ were all in Hardy-Weinberg equilibrium ( $P$ equalling $0.47,0.34$ and 0.92 respectively).

\section{Association between fat mass and genotype}

Neither of the SNPs analysed were significantly associated with TBFM or BMI before or after adjustments for potentially confounding factors (Table 2).

The rs806381 polymorphism appeared associated with abdominal FM with higher levels found in homozygous of the mutant allele; however, no significant trend was found. No significant association between this genotype and intermuscular, femoral or abdominal subcutaneous FM was found (Fig. 1A and Table 2).

The rs10485179 polymorphism was not associated with either of the measures of FM in this study (Fig. 1B and Table 2).

Visceral and intermuscular FM were associated with the rs1049353 polymorphism with tests suggesting an additive effect. Visceral and inter-femoral FM were significantly higher in homozygous of the wild-type allele (Fig. 1C and Table 2). These associations between genotypes of the rs1049353 SNP, and both visceral and intermuscular FM remained significant after adjustment for age, alcohol consumption and smoking status $(r=0.16, P=0.002$ and $r=0.138, P=0.006$ respectively). Concurrently, WHR was borderline higher in carriers of wild-type alleles $(P=0.053)$.

Neither abdominal subcutaneous nor femoral FM was associated with this genotype (Table 2).

\section{Association between insulin sensitivity, lipids and genotype}

None of the SNPs were significantly associated with fasting glucose or homeostasis model assessment for insulin resistance (HOMA-IR; Table 2) in crude analysis.
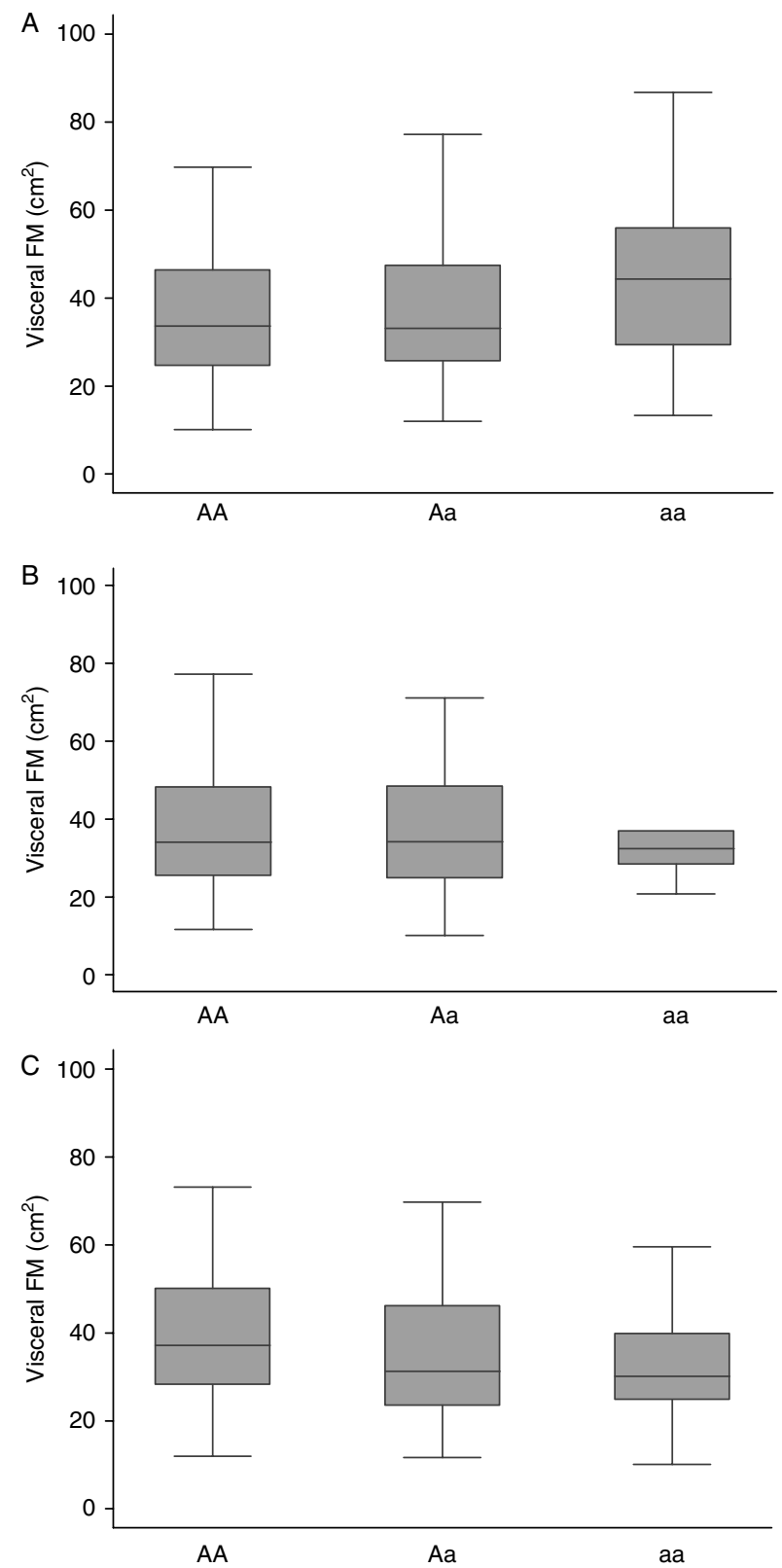

Figure 1 Distribution of visceral fat mass by genotypes A, rs806381; B, rs10485179; C, rs1049353. 
Carriers of the wild-type allele in the rs10485179 polymorphism appeared to have a higher level of triglycerides compared with the other participants; however, the observation was not statistically significant, perhaps because only nine participants were homozygous for the mutant allele in the rs10485179 polymorphism. Participants carrying the wild-type allele in the rs1049353 SNP also had a higher level of triglycerides $(P=0.021)$, and genotype remained associated with levels of triglyceride after adjustment $(r=0.100 ; P=0.006)$.

\section{Discussion}

Our study demonstrates that the rs1049353 SNP of the CNR1 is linked with visceral FM in a population of young, healthy men. Also, our data suggests a relation between the polymorphisms of the CNR 1 and another of the main outcomes, intermuscular FM, as well as levels of triglycerides. Conversely, none of the polymorphisms were linked with subcutaneous or TBFM or estimates of insulin resistance.

Our data suggests an association between the common allele of the rs1049353 polymorphism and visceral as well as intermuscular FM. Carriers of the wild-type allele tended to have higher levels of FM at these sites as well as higher levels of serum triglycerides.

Conversely, BMI and TBFAT were not significantly associated with the genotypes examined. Previously, carriers of the common allele of the rs1049353 SNP have been shown to have lower WHRs and FM as measured by bio-impedance (10). These participants, however, were obese and older than our study population. Although both cohorts consisted of Caucasians, environmental differences and an age-dependent effect may account for the observed differences. Estimates of body composition based on bio-impedance and DXA may diverge (18), and contrary to MRI, bio-impedance cannot separate visceral from subcutaneous FM. MRI, on the other hand, comes with issues as it is more difficult to perform (19) - something that may influence our results of measures of femoral FM in particular.

In our study, the rs806381 polymorphism was borderline associated with visceral FM but not intermuscular FM. Recent studies have disagreed on the effect of this polymorphism on measures of obesity ranging from an association with child and adulthood obesity or BMI in Swiss, French and Danish study populations (14) to complete absence of a relation in the Framingham Study and in a community-based selection of people of European ancestry (13). The difference between our results and those previously published on the rs806381 polymorphism may be accounted for by differences in study populations and variation in the methods used for estimation of obesity as well as gender and the size of the study populations. Furthermore, evaluations of the rs2023239 $(12,14)$ have suggested age-dependent effects of the polymorphism on BMI, which potentially could also be the case for other polymorphisms.

The rs10485179 SNP appeared to be linked to the level of triglycerides, whereas no associations with other markers of metabolic dysfunction were ascertained. Although the rs10485179 polymorphism previously has been strongly linked to obesity and BMI (14), we were unable to replicate those results. Our relatively small study comprising very few homozygous for the mutant allele of the rs10485179 SNP may be the reason for the diverging findings.

Studies on associations between polymorphisms of the CNR 1 have been performed with different estimates of fat distribution and in divergent study populations; however, several factors influence body composition and the methods used for the estimates. Sexual dimorphism affects body composition with higher levels of FM in women and significantly larger waist circumference in men (14), while the visceral FM increases by age in both genders (20).

Visceral FM is strongly associated with an undesirable metabolic profile (21). Furthermore, intermuscular FM is related to risk factors of cardiovascular disease independently of visceral FM (22), and in type II diabetics, the levels of intermuscular and visceral FM are higher than in controls (23).

Our findings on an association between a common polymorphism in the CNR1 and both visceral and intermuscular FM link the endocannabinoid system with common risk factors of metabolic disorders including type II diabetes and cardiovascular diseases. Although the effect of the polymorphism on the function of the CB1 is unknown, the results favour further evaluations of the endocannabinoid system.

Our study has some limitations. First, the study population was relatively small, all participants were Caucasians of Danish origin, comprised a narrow age span and males only. Secondly, we analysed only a limited number of polymorphisms of the CNR1. Thirdly, the study included several outcomes. Although special emphasis was given to MRI-derived measurements of FM, the problems associated with multiple testing, i.e. the risk of chance association, should be acknowledged, and the results will require replication in other cohorts. Since the outcomes are likely to be correlated, a Bonferroni correction for multiple testing was believed to be too conservative. On the other hand, the study was population based. Also, MRI was used for an exact evaluation of fat distribution, and markers of metabolic dysfunction were evaluated.

We conclude that common variants in the CNR1 may be associated with visceral FM rather than subcutaneous FM. Moreover, polymorphisms of the CNR1 may also be related to intermuscular FM. Even though neither of the polymorphisms was related to levels of glucose or cholesterol, the results underline the connection between the endocannabinoid system and FM. 


\section{Declaration of interest}

The authors declare that there is no conflict of interest that could be perceived as prejudicing the impartiality of the research reported.

\section{Funding}

$\mathrm{S}$ Beckers is a post-doctoral researcher of the Fund of Scientific Research Flanders (FWO-Vlaanderen). The study received financial support from The Velux Foundation, World Anti-Doping Agency, Novo Nordisk AB, The Danish Ministry of Culture and The Clinical Institute at the University of Southern Denmark, Odense.

\section{References}

1 Howlett AC, Barth F, Bonner TI, Cabral G, Casellas P, Devane WA, Felder CC, Herkenham M, Mackie K, Martin BR, Mechoulam R \& Pertwee RG. International Union of Pharmacology. XXVII. Classification of cannabinoid receptors. Pharmacological Reviews 200254 161-202. (doi:10.1124/pr.54.2.161)

2 Matias I \& Di Marzo V. Endocannabinoids and the control of energy balance. Trends in Endocrinology and Metabolism 200718 27-37. (doi:10.1016/j.tem.2006.11.006)

3 Eckardt K, Sell H, Taube A, Koenen M, Platzbecker B, Cramer A, Horrighs A, Lehtonen M, Tennagels N \& Eckel J. Cannabinoid type 1 receptors in human skeletal muscle cells participate in the negative crosstalk between fat and muscle. Diabetologia 200952 664-674. (doi:10.1007/s00125-008-1240-4)

4 Van Gaal LF, Scheen AJ, Rissanen AM, Rossner S, Hanotin C \& Ziegler O. Long-term effect of CB1 blockade with rimonabant on cardiometabolic risk factors: two year results from the RIO-Europe Study. European Heart Journal 200829 1761-1771. (doi:10. 1093/eurheartj/ehn076)

5 Despres JP, Golay A \& Sjostrom L. Effects of rimonabant on metabolic risk factors in overweight patients with dyslipidemia. New England Journal of Medicine 2005353 2121-2134. (doi:10. 1056/NEJMoa044537)

6 Pi-Sunyer FX, Aronne LJ, Heshmati HM, Devin J \& Rosenstock J. Effect of rimonabant, a cannabinoid-1 receptor blocker, on weight and cardiometabolic risk factors in overweight or obese patients: RIO-North America: a randomized controlled trial. Journal of the American Medical Association 2006295 761-775. (doi:10.1001/ jama.295.7.761)

7 Scheen AJ, Finer N, Hollander P, Jensen MD \& Van Gaal LF. Efficacy and tolerability of rimonabant in overweight or obese patients with type 2 diabetes: a randomised controlled study. Lancet $2006 \mathbf{3 6 8}$ 1660-1672. (doi:10.1016/S0140-6736(06)69571-8)

8 Di Marzo V, Goparaju SK, Wang L, Liu J, Bátkai S, Járai Z, Fezza F, Miura GI, Palmiter RD, Sugiura T \& Kunos G. Leptin-regulated endocannabinoids are involved in maintaining food intake. Nature 2001410 822-825. (doi:10.1038/35071088)

9 Osei-Hyiaman D, DePetrillo M, Pacher P, Liu J, Radaeva S, Bátkai S, Harvey-White J, Mackie K, Offertáler L, Wang L \& Kunos G. Endocannabinoid activation at hepatic CB1 receptors stimulates fatty acid synthesis and contributes to diet-induced obesity. Journal of Clinical Investigation 2005115 1298-1305. (doi:10. 1172/JCI23057)

10 Peeters A, Beckers S, Mertens I, Van Hul W \& Van Gaal L. The G1422A variant of the cannabinoid receptor gene (CNR1) is associated with abdominal adiposity in obese men. Endocrine 2007 31 138-141. (doi:10.1007/s12020-007-0022-y)

11 Gazzerro P, Caruso MG, Notarnicola M, Misciagna G, Guerra V, Laezza C \& Bifulco M. Association between cannabinoid type-1 receptor polymorphism and body mass index in a Southern Italian population. International Journal of Obesity 200731 908-912. (doi:10.1038/sj.ijo.0803510)

12 Müller TD, Reichwald K, Wermter AK, Brönner G, Nguyen TT, Friedel S, Koberwitz K, Engeli S, Lichtner P, Meitinger T, Schäfer H, Hebebrand J \& Hinney A. No evidence for an involvement of variants in the cannabinoid receptor gene (CNR1) in obesity in German children and adolescents. Molecular Genetics and Metabolism 2007 90 429-434. (doi:10.1016/j.ymgme.2007.01.002)

13 Lieb W, Manning AK, Florez JC, Dupuis J, Cupples LA, McAteer JB, Vasan RS, Hoffmann U, O'Donnell CJ, Meigs JB \& Fox CS. Variants in the CNR1 and the FAAH genes and adiposity traits in the community. Obesity 200917 755-760. (doi:10.1038/oby.2008. 608)

14 Benzinou M, Chèvre JC, Ward KJ, Lecoeur C, Dina C, Lobbens S, Durand E, Delplanque J, Horber FF, Heude B, Balkau B, BorchJohnsen K, Jørgensen T, Hansen T, Pedersen O, Meyre D \& Froguel P. Endocannabinoid receptor 1 gene variations increase risk for obesity and modulate body mass index in European populations. Human Molecular Genetics 200817 1916-1921. (doi:10.1093/hmg/ddn089)

15 Nielsen TL, Wraae K, Brixen K, Hermann AP, Andersen M \& Hagen C. Prevalence of overweight, obesity and physical inactivity in 20- to 29-year-old, Danish men. Relation to sociodemography, physical dysfunction and low socioeconomic status: the Odense Androgen Study. International Journal of Obesity 200630 805815. (doi:10.1038/sj.ijo.0803197)

16 Nielsen TL, Hagen C, Wraae K, Brixen K, Petersen PH, Haug E, Larsen R \& Andersen M. Visceral and subcutaneous adipose tissue assessed by magnetic resonance imaging in relation to circulating androgens, sex hormone-binding globulin, and luteinizing hormone in young men. Journal of Clinical Endocrinology and Metabolism 200792 2696-2705. (doi:10.1210/jc.2006-1847)

17 Altman DG. Practical Statistics for Medical Research, 1991 London: Chapman \& Hall.

18 Volgyi E, Tylavsky FA, Lyytikainen A, Suominen H, Alen M \& Cheng S. Assessing body composition with DXA and bioimpedance: effects of obesity, physical activity, and age. Obesity 2008 16 700-705. (doi:10.1038/oby.2007.94)

19 Gallagher D, Kuznia P, Heshka S, Albu J, Heymsfield SB, Goodpaster B, Visser M \& Harris TB. Adipose tissue in muscle: a novel depot similar in size to visceral adipose tissue. American Journal of Clinical Nutrition 200581 903-910.

20 Wajchenberg BL. Subcutaneous and visceral adipose tissue: their relation to the metabolic syndrome. Endocrine Reviews 200021 697-738. (doi:10.1210/er.21.6.697)

21 Fox CS, Massaro JM, Hoffmann U, Pou KM, Maurovich-Horvat P, Liu CY, Vasan RS, Murabito JM, Meigs JB, Cupples LA, D’Agostino RB Sr \& O'Donnell CJ. Abdominal visceral and subcutaneous adipose tissue compartments: association with metabolic risk factors in the Framingham Heart Study. Circulation 2007116 39-48. (doi:10. 1161/CIRCULATIONAHA.106.675355)

22 Yim JE, Heshka S, Albu JB, Heymsfield S \& Gallagher D. Femoralgluteal subcutaneous and intermuscular adipose tissues have independent and opposing relationships with CVD risk. Journal of Applied Physiology 2008 104 700-707. (doi:10.1152/japplphysiol.01035.2007)

23 Gallagher D, Kelley DE, Yim JE, Spence N, Albu J, Boxt L, Pi-Sunyer FX \& Heshka S. Adipose tissue distribution is different in type 2 diabetes. American Journal of Clinical Nutrition $2009 \mathbf{8 9}$ 807-814. (doi:10.3945/ajcn.2008.26955)

Received 31 May 2010

Accepted 28 June 2010 